\title{
PENINGKATAN PENGETAHUAN IBU HAMIL TENTANG DETEKSI DINI PLACENTA PREVIA MELALUI PENYULUHAN DI DESA KEMANG INDAH KEC. TAMBANG KABUPATEN KAMPAR
}

\author{
Wan Anita ${ }^{1 *}$, Lita Nafratilova ${ }^{2}$ \\ Prodi D III Kebidanan STIKes Tengku Maharatu ${ }^{1,2}$ \\ e-mail*: wan_anita77@yahoo.co.id
}

\begin{abstract}
Abstrak - Penyebab perdarahan yang terjadi pada ibu hamil adalah plasenta previa. Beberapa faktor yang dapat mengakibatkan ibu hamil mengalami plasenta previa yaitu multiparitas dan umur lanjut ( $>35$ tahun), paritas, riwayat seksio sesaria dan perokok. Prevalensi placenta previa meningkat tiga kali lipat pada usia di atas 35 tahun karena endometrium tidak subur. Jumlah kematian ibu di Propinsi Riau tahun 2018 sebanyak 109 kasus dengan penyebab utama kematian adalah perdarahan $34 \%$. Berbagai upaya dilakukan untuk meningkatkan pengetahuan seseorang salah satunya adalah penyuluhan kesehatan. Pelaksanaan pengabdian masyarakat yang telah dilakukan di Desa Kemang Indah Kec. Tambang Kab. Kampar, terdapat 11 responden $(68,75 \%)$ dengan usia $<20$ tahun $>35$ tahun, terdapat 15 responden $(93,75 \%)$ dengan paritas $2-3$, terdapat 15 responden $(93,75 \%)$ dengan tidak pernah riwayat SC, terdapat 16 responden (100\%) dengan tidak ada riwayat SC dan tidak perokok. Nilai mean pengetahuan responden pre test adalah 35 dan post test adalah 70 . Kesimpulan pengabdian ini adalah adanya peningkatan pengetahuan ibu hamil tentang deteksi dini placenta previa. Diharapkan dari hasil pengabdian ibu hamil dapat bisa melakukan deteksi tentang faktor resiko kejadian placenta previa untuk menghindari kasus perdarahan yang dapat menyebabkan kematian ibu hamil.
\end{abstract}

Kata kunci : deteksi dini, hamil, placenta previa

Abstract - The cause of bleeding that occurs in pregnant women is placenta previa. Several factors that can cause pregnant women to experience placenta previa are multiparity and advanced age (> 35 years), parity, history of cesarean section and smoking. The prevalence of placenta previa increases threefold at the age of 35 years because the endometrium is infertile. The number of maternal deaths in Riau Province in 2018 was 109 cases, with the main cause of death being bleeding $34 \%$. Various efforts have been made to increase one's knowledge, one of which is health education. Implementation of community service that has been carried out in the Village of Kemang Indah, Kec. Tambang Kab. Kampar, there were 11 respondents $(68.75 \%)$ with ages <20 years> 35 years, there were 15 respondents $(93.75 \%)$ with parity of 2-3, there were 15 respondents $(93.75 \%)$ with never had a history of SC, there were 16 respondents (100\%) with no history of SC and no smoker. The mean value of the pre-test respondents' knowledge was 35 and the post-test was 70 . The conclusion of this dedication is that there is an increase in the knowledge of pregnant women about early detection of placenta previa. It is hoped that the results of the dedication of pregnant women can detect risk factors for placenta previa to avoid cases of bleeding that can cause the death of pregnant women.

Keyword: detection, pregnancy, placenta previa

\section{PENDAHULUAN}

Kematian maternal adalah kematian seorang wanita waktu hamil atau dalam 42 hari sesudah berakhirnya kehamilan oleh sebab apapun, terlepas dari tuanya kehamilan dan tindakan yang dilakukan 
untuk mengakhiri kehamilan. Angka kematian maternal (Maternal Mortality Rate) adalah jumlah kematian maternal diperhitungkan terhadap 100.000 kelahiran hidup. Hasil SDKI tahun 2012, Angka Kematian Ibu (AKI) yaitu sebanyak 359/ 100.000. Jumlah kematian ibu di Propinsi Riau tahun 2018 sebanyak 109 kasus dengan penyebab utama kematian adalah perdarahan $34 \%$ (Dinas Kesehatan Propinsi Riau, 2018).

Perdarahan yang terjadi pada ibu hamil salah satunya disebabkan oleh plasenta previa. Plasenta previa adalah plasenta yang letaknya abnormal, yaitu pada segmen bawah uterus sehingga menutupi sebagian atau seluruh pembukaan jalan lahir, perdarahan ini biasanya terdapat pada usia kehamilan 22 minggu (Ratna, 2013). Plasenta merupakan suatu organ yang terbentuk pada dinding sebelah dalam uterus segera setelah terjadi pembuahan. Zat-zat makanan dan oksigen akan didistribusikan dari ibu ke janinnya melalui plasenta serta membawa sisa-sisa metabolisme ke luar dari tubuh janin. Normalnya, plasenta melekat pada dinding atas uterus (Sugianto, 2011).

Ada beberapa faktor yang dapat mengakibatkan ibu hamil mengalami plasenta previa diantaranya yaitu multiparitas dan umur lanjut (>35 tahun), paritas, riwayat pembedahan rahim termasuk seksio sesaria dan perokok
(Varney, 2007). Plasenta previa memiliki beberapa faktor risiko yaitu usia, paritas, riwayat seksio sesaria dan riwayat abortus. Menurut Manuaba (2010) prevalensi placenta previa akan meningkat tiga kali lipat pada usia di atas 35 tahun karena endometrium akan menjadi kurang subur. Pada penelitian oleh Tabassum et al. (2010) di Pakistan mendapatkan bahwa usia adalah salah satu faktor risiko dari plasenta previa, yaitu usia $=35$ tahun memiliki risiko hampir 2 kali lebih besar dibandingkan usia $<35$ tahun, serta ibu dengan riwayat seksio sesaria pada kelahiran sebelumnya memiliki risiko 4,5 kali mengalami plasenta. Hasil penelitian oleh Abdat di Rumah Sakit dr. Moewardi Surakarta tahun 2010 mendapatkan risiko terjadinya plasenta previa pada ibu multiparitas meningkat 2,53 kali (Hartono, dkk, 2012). Penelitian yang dilakukan oleh Hung, dkk (2007) terdapat 457 $(1,2 \%)$ kasus plasenta previa dan There were 457 dari 37.702 kehamilan. Hasil menunjukkan adanya resiko 2 kali pada usia lebih dari 35 tahun dan 1,3 kali pada riwayat induksi abortus. Cunningham (2001) menyatakan kejadian placenta previa akan meningkat pada wanita yang sudah melakukan 2 kali atau lebih operasi caesar. Mochtar (2008) juga menyatakan melahirkan dengan operasi caesar adalah melahirkan janin dengan sayatan pada dinding uterus, sayatan inilah yang dapat 
mengakibatkan parut di dalam rahim sehingga meningkatkan kemungkinan terjadinya placenta previa. Penelitian yang dilakukan oleh Miller et all (1996) ditemukan hasil bahwa wanita dengan placenta previa yang mempunyai usia lebih dari 35 tahun beresiko 2,28 kali untuk terjadi placenta akreta, riwayat section secarea lebih dari 2 kali beresiko 11,32 kali untuk terjadi placenta acreta. Penelitian oleh Jhonson et all (2003) menunjukkan peningkatan resiko plasenta previa disebabkan oleh kuretase pada kasus abortus.

Perdarahan obstetri yang terjadi pada kehamilan trimester ketiga dan yang terjadi setelah anak atau plasenta lahir pada umumnya adalah perdarahan yang berbahaya, dan jika tidak mendapat penanganan yang cepat bisa mendatangkan syok yang fatal. Oleh sebab itu, perlulah keadaan ini diantisipasi secara dini selagi perdarahan belum sampai ke tahap yang membahayakan ibu dan janinnya. Antisipasi dalam perawatan prenatal adalah sangat mungkin karena pada umumnya penyakit ini berlangsung perlahan diawali gejala dini berupa perdarahan berulang yang mulanya tidak banyak tanpa disertai rasa nyeri dan terjadi pada waktu yang tidak tertentu, tanpa trauma. Sering disertai oleh kelainan letak janin atau pada kehamilan lanjut bagian bawah janin tidak masuk ke dalam panggul, tetapi masih mengambang di atas pintu atas panggul. Perempuan hamil yang menderita plasenta previa harus segera dirujuk dan diangkut ke rumah sakit terdekat tanpa melakukan periksa dalam karena perbuatan tersebut memprovokasi perdarahan berlangsung semakin deras dan cepat (Prawirohardjo, 2010).

Hasil penelitian yang dilakukan oleh Anita (2017) Hasil penelitian menunjukkan terdapat hubungan paritas 1 dan $>3$ terhadap kejadian placenta previa $(p$ value $=0,034)$ dan penelitian Anita (2016) didapatkan hasil mayoritas riwayat Sectio Caesar adalah Pernah sc minimal 1x yaitu berjumlah 33 orang $(82,5 \%)$; mayoritas kejadian Plasenta Previa adalah Plasenta Totalis yaitu berjumlah 25 orang $(62,5 \%)$; terdapat hubungan yang signifikan antara Riwayat Sectio Caesar dengan Kejadian dengan Plasenta Previa hasil $p$ value $0,001>0,05$.

Pengetahuan adalah hasil pengindraan manusia, atau hasil tahu seseorang terhadap objek melalui indra yang dimilikinya. Dengan sendirinya pada waktu pengindraan sehingga menghasilkan pengetahuan tersebut sangat dipengaruhi oleh intensitas perhatian dan persepsi terhadap objek (Notoatmojo, 2010). Berbagai upaya dilakukan untuk meningkatkan pengetahuan seseorang salah satunya adalah penyuluhan kesehatan. 
Penyuluhan adalah proses perubahan perilaku dikalangan masyarakat agar mereka tahu, mau dan mampu melakukan perubahan demi tercapainya peningkatan produksi, pendapatan atau keuntungan dan perbaikan kesejahteraannya (Subejo, 2010).

Permasalahan pada pengabdian masyarakat ini adalah "masih tingginya angka kematian ibu akibat perdarahan terutama placenta previa dan masih rendahnya pengetahuan sehingga diperlukan edukasi pada ibu hamil tentang faktor resiko placenta previa melalui penyuluhan."

\section{METODE KEGIATAN}

Metode pengabdian masyarakat berupa edukasi / peningkatan pengetahuan ibu hamil tentang faktor resiko plasenta previa melalui penyuluhan di Desa Kemang Indah Kecamatan Tambang Kabupaten Kampar pada tanggal 3 September 2020 dengan responden adalah ibu hamil. Penilaian pengetahuan melalui keuisioner pre dan post test. Analisis serta indikator keberhasilan PKM berupa analisis univariat dalam bentuk distribusi frekuensi dan nilai mean (rata-rata) peningkatan nilai pengetahuan audience setelah antara sebelum dan sesudah diberikan penyuluhan.

\section{HASIL DAN PEMBAHASAN}

Adapun hasil dari pelaksanaan pengabdian masyarakat sebagai berikut

a. Distribusi Frekuensi audience berdasarkan usia

Tabel 1

Distribusi Frekuensi audience berdasarkan usia

\begin{tabular}{|c|c|c|c|}
\hline No & Kategori & $\mathrm{f}$ & $\%$ \\
\hline \multicolumn{4}{|l|}{ Usia } \\
\hline 1 & $<20$ tahun $/>35$ tahun & 11 & 68,75 \\
\hline 2 & 20-35 tahun & 5 & 31,25 \\
\hline \multicolumn{2}{|l|}{ Total } & 16 & 100,00 \\
\hline \multicolumn{4}{|c|}{ Paritas } \\
\hline 1 & 1 atau $>3$ & 1 & 6,25 \\
\hline 2 & $2-3$ & 15 & 93,75 \\
\hline \multicolumn{2}{|l|}{ Total } & 16 & 100,00 \\
\hline \multicolumn{4}{|c|}{ Riwayat SC } \\
\hline 1 & Pernah SC & 1 & 6,25 \\
\hline 2 & Tidak Pernah SC & 15 & 93,75 \\
\hline \multicolumn{2}{|l|}{ Total } & 16 & 100,00 \\
\hline \multicolumn{4}{|c|}{ Riwayat penyakit pada rahim } \\
\hline 1 & Ada riwayat penyakit pada rahim & 0 & 0 \\
\hline 2 & Tidak ada riwayat penyakit pada rahim & 16 & 100,00 \\
\hline \multicolumn{2}{|r|}{ - } & 16 & 100,00 \\
\hline \multicolumn{4}{|c|}{ Perokok } \\
\hline 1 & Perokok & 0 & 0 \\
\hline 2 & Tidak perokok & 16 & 100,00 \\
\hline \multicolumn{2}{|l|}{ Total } & 16 & 100,00 \\
\hline
\end{tabular}


Berdasarkan tabel di atas mayoritas terdapat 11 audience $(68,75 \%)$ dengan usia <20 tahun > 35 tahun, terdapat 15 audience $(93,75 \%)$ dengan paritas 2-3, terdapat 15 audience $(93,75 \% 0$ dengan tidak pernah riwayat SC, terdapat 16 audience (100\%) dengan tidak ada riwayat penyakit pada rahim dan terdapat 16 audience (100\%) dengan tidak perokok.

b. Distribusi Frekuensi nilai mean pengetahuan audience berdasarkan kuisioner pre test dan post test

\section{Tabel 2}

Nilai mean pengetahuan audience berdasarkan kuisioner pre test dan post test

\begin{tabular}{|c|c|c|c|c|c|c|c|}
\hline \multirow[b]{2}{*}{ No } & \multirow[b]{2}{*}{$\begin{array}{c}\text { Nilai } \\
\text { Kuisioner }\end{array}$} & \multicolumn{2}{|c|}{ Pre Test } & \multicolumn{2}{|c|}{ Post Test } & \multicolumn{2}{|c|}{ Nilai Mean } \\
\hline & & $\mathrm{f}$ & $\%$ & $\mathrm{f}$ & $\%$ & $\begin{array}{l}\text { Pre } \\
\text { Test }\end{array}$ & $\begin{array}{l}\text { Post } \\
\text { Test }\end{array}$ \\
\hline 1 & Nilai 0 & 1 & 6,25 & 0 & 0 & \multirow{7}{*}{35} & \multirow{7}{*}{70} \\
\hline 2 & Nilai 20 & 7 & 73,75 & 2 & 12,5 & & \\
\hline 3 & Nilai 40 & 3 & 18,75 & 1 & 6,25 & & \\
\hline 4 & Nilai 60 & 5 & 31,25 & 4 & 25 & & \\
\hline 5 & Nilai 80 & 0 & 0 & 5 & 31,25 & & \\
\hline 6 & Nilai 100 & 0 & 0 & 4 & 25 & & \\
\hline \multicolumn{2}{|c|}{ Total } & 16 & 100,00 & 16 & 100,00 & & \\
\hline
\end{tabular}

Berdasarkan tabel di atas, nilai mean (nilai rata-rata) pengetahuan responden berdasarkan pengisian kuisioner pre test adalah 35 dan pengisiian kuisioner post test adalah 70 .

\section{KESIMPULAN DAN SARAN}

Terjadi peningkatan pengetahuan ibu hamil tentang deteksi dini placenta previa melalui penyuluhan di Desa Kemang Indah Kec. Tambang Kabupaten Kampar dengan rata-rata nilai sebelum penyuluhan 35 dan nilai setelah penyuluhan menjadi 70. Perlunya peningkatan pengetahuan ibu hamil berkelanjutan dalam bentuk kelompok ibu hamil, kelompok senam hamil dengan menyisipkan materi penyuluhan agar pengetahuan ibu semakin meningkat dengan berbagi pengetahuan dan pengalaman sesama ibu hamil.

\section{DAFTAR PUSTAKA}

Cuningham et al. 2001. Obstetri Williams. Edisi 21. Jakarta: EGC.

Depkes. 2012. Kematian Maternal. http://www.depkes.go.id/index.php ?vw=2\&id=2127

Faiz AS dkk. 2003. Etiology and risk factors for placenta previa: An overview and meta analysis of observational studies. Journal of Maternal Fetal and Neonatal Medicine. Volume 13 : 175-190

Hartono. 2011. Faktor Risiko Kejadian Plasenta Previa Pada Ibu Hamil di 
RSU dr.Soedarso. Pontianak, Indonesia.

Hung TH dkk 2007. Risk factors for placenta previa in an Asian population. International Journal of Gynecology and Obstetric. Volume 97 : 26-30

Johnson LG, et all. 2003. The Relationship of Placenta Previa and History of Induced Abortion. International Journal of Gynecology and Obstetrics. Volume 81 : 191-198

Manuaba, 2010. Gawat Darurat Ginekologi dan Obstetri Ginekologi Sosial untuk Profesi Bidan. Jakarta : EGC

Miller, et all. 1996. Clinical Risk Factors For Placenta Previa - Placenta Accreta. America Journal Obstetric Gynecologyc Number 1 Volume 177

Mochtar R 2008. Sinopsis Obstetri Jilid I. Jakarta : EGC.
Prawirohardjo, S. 2010. Ilmu Kebidanan. Jakarta : Yayasan Bina Pustaka

Ramaye. 2014. Riwayat SC. http://ramaye.blogspot.com/2014/0 1/plasenta-previa.html

Ratna. 2013. Plasenta Previa. http://bidanaktif.blogspot.com/2013/04/faktorfaktor-yang-berhubungandengan_1149.html

SDKI. 2012. SDKI tahun 2012. http://nasional.sindonews.com/read /2013/09/25/15/787480/data-sdki2012-angka-kematian-ibumelonjak

Sugianto. 2011. Plasenta Previa. http://anthogoodwillstiabone.blogspot.com/2011/07/asu han-kebidanan-komprehensif-padanyh.html

Suparyanto. 2010. Paritas. http://drsuparyanto.blogspot.com/2010/10/ konsep-paritas-partus.html

Varney et al 2007. Buku Ajar Asuhan Kebidanan. Jakarta: EGC. 